\title{
Elementos Alu en el análisis filogenético molecular del infraorden Platyrrhini, Primates
}

\author{
Bertha Ludeña, Juan Carlos Escobar, Jean-Christophe Pintaud \\ Laboratorio de Genética Molecular de Eucariotes \\ Pontificia Universidad Católica del Ecuador \\ 17-01-2184 Quito-Ecuador. \\ Recibido 1 abril 2005 , aprobado 15 de junio 2005
}

\begin{abstract}
RESUMEN. Los marcadores moleculares Alu: STK1, VP y HBGF fueron utilizados en el presente trabajo para analizar la filogenia de algunas especies de platirrinos ecuatorianos. Los resultados positivos para la amplificación genómica de estos marcadores en las especies estudiadas: Cebus albifrons, Saimiri sciureus, Ateles belzebuth, Ateles fusciceps, Alouatta palliata y Lagothrix lagotricha revelan que eventos derivados de transposición de elementos Alu han tenido relación con la filogenia de los primates del Nuevo Mundo.

El análisis mediante Neighbor-joining de la información obtenida ratifica el posicionamiento de los géneros Alouatta, Ateles y Lagothrix en la familia Atelidae y sugiere una estrecha cercanía entre los géneros Cebus y Saimiri apoyando la inclusión de éstos en un clado.
\end{abstract}

PALABRAS ClAVE. Análisis filogenético, evolución, marcadores genómicos Alu, platirrinos.

\begin{abstract}
Molecular markers Alu: STK1,VP and HBGF were applied to the phylogenetic analysis of some ecuadorian platyrrhines. PCR amplification for all three markers was positive in the analysed species: Cebus albifrons, Saimiri sciureus, Ateles belzebuth, Ateles fusciceps, Allouata palliata and Lagothrix lagotricha. This shows that derived Alu- transpositions originated during New World monkey evolution.

Neighbor- joining analysis of this information supports the positioning of genera

Alouatta, Ateles and Lagotricha in Atelidae family and a close affiliation between genera Cebus and Saimiri which could be considered as a clade.
\end{abstract}

KEYWORDS. Phylogenetic analysis, evolution, Alu generic markers, Platyrrhines.

\section{INTRODUCCIÓN}

Existe un consenso general respecto a la monofilia del grupo de los primates antropoideos, es decir que tanto Catarrhini (monos del Viejo Mundo) como Platyrrhini (monos del Nuevo Mundo) descienden de un ancestro común.

Respecto a la aparición de los Monos del Nuevo Mundo, los primeros registros fósiles datan del Deseadánico y Colhuehuagiano en Bolivia y Argentina (edades anteriores al Oligoceno). En aquella época Sud América era una isla separada de otros continentes por grandes expansiones de océano. Se sugiere que en los límites entre Eoceno y Oligoceno, tuvieron lugar cambios climáticos drásticos afectando el nivel del mar. En este ambiente, las dorsales del sur del océano Atlántico quedaron al descubierto formando islas, creando así vías que pudieron haber favorecido la migración de fauna desde Africa hacia el aislado continente de Sud América $(1,2)$.

Los monos del Nuevo Mundo así como otros mamíferos tienen relaciones de taxones hermanos con grupos africanos, por tanto la existencia de una relación faunística entre Africa y Sud América en la transición Eoceno, Oligoceno es fuertemente corroborada. (3).

Los platirrinos actuales se encuentran asignados a 16 géneros o subgéneros, 12 de los cuales pertenecen a tres grupos monofiléticos: los Pitheciidae/Pitheciinae, los Atelidae/Atelinae y los Callitrichidae/Callitrichinae. 
De acuerdo a la clasificación taxonómica de Goodman et al. (4), estos grupos pueden ser considerados como subfamilias. Respecto a las relaciones filogenéticas de los géneros Cebus, Saimiri, Callicebus y Aotus hasta el momento resulta difícil definirlas.

Es importante señalar que existe una fuerte evidencia que indicaría un origen monofilético de los primates de América Central y América del Sur, sustentada en el análisis de secuencias de $\operatorname{ADN}(5,6,7,8,9)$.

En el Ecuador han sido descritas 19 especies de platirrinos (10) representadas por los géneros: Callithrix (Cebuella), Saguinus, Saimiri, Cebus, Aotus, Callicebus, Pithecia, Alouatta, Ateles y Lagothrix.

En el presente trabajo se aborda la problemática filogenética en platirrinos ecuatorianos mediante el análisis de los elementos Alu: en el gen de la Tirosina kinasa de Células Madre (STK1), en el intrón 4 del pigmento visual (VP) y en el precursor del factor del crecimiento similar a EGF de unión a la heparina (HBGF). Los mencionados marcadores genómicos hacen parte de una familia de elementos nucleares cortos interdispersos en el genoma de primates (SINES). Los SINES constituyen marcadores cladísticos que revelan sinapomorfías moleculares y son útiles para establecer relaciones de taxa en términos generales (11).

El presente análisis de elementos nucleares específicos de primates (SINES) ha sido efectuado en el genoma de individuos de las siguientes especies:

Cebus albifrons, Saimiri sciureus, Ateles belzebuth, Ateles fusciceps, Alouatta palliata y Lagothrix lagotricha

\section{MATERIALES Y MÉTODOS}

\section{Muestras biológicas}

El ADN para este estudio ha sido extraído a partir de sangre venosa periférica (alrededor de $1 \mathrm{ml}$ ), tomada de individuos en cautiverio o cazados por indígenas.
De la sangre obtenida se ha procedido a realizar la extracción de DNA mediante shock hipotónico y digestión en presencia de proteinasa $\mathrm{K}$. Los ácidos nucleicos han sido separados utilizando cloroformo: alcohol isoamílico y precipitados con etanol.

El material obtenido ha sido mantenido en Robert's buffer y su concentración y calidad han sido verificadas en gel de agarosa al $1 \%$ (Figura 1).

Figura 1. Resultados de extracción de ADN

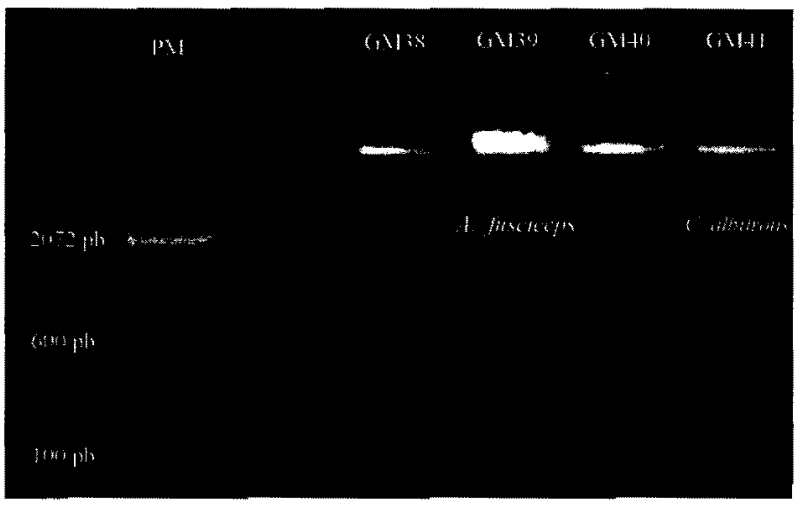

El ADN extraído a partir de sangre periférica de primates del Nuevo Mundo es cuantificado y calificado en geles de agarosa al 1\%. En la figura se ilustra los resultados obtenidos para dos individuos de Ateles fusciceps y dos individuos de Cebus albifrons.

\section{Amplificación mediante PCR}

Para la amplificación de los elementos Alu, se utilizó los oligonucleótidos diseñados por Singer et al, 2003. La reacción de PCR se efectuó en 12,5ul de volumen final incluyendo $30 \eta \mathrm{g}$ de ADN, oligonucleótidos forward y reverse en concentración $20 \mathrm{mM}$, buffer FailSafe premix 1X (Epicentre, Madisson,USA)y 0,5U de Platinum Taq polimerasa (Invitrogen). Los programas de amplificación correspondieron a 2 minutos de pre-denaturación a $92^{\circ} \mathrm{C}$ y 30 ciclos de 45 segundos de denaturación a $92^{\circ} \mathrm{C}, 60$ segundos de acoplamiento a la temperatura correspondiente a cada par de oligonucleótidos y 60 segundos a $72^{\circ} \mathrm{C}$ para la extensión. Los productos de PCR fueron visualizados en geles de agarosa junto a un marcador de peso molecular y registrados mediante fotografía (Figura 2). El análisis de las dimensiones de los amplificados 
obtenidos fue hecho con el programa PhotoCapt MW V.10.01. Posteriormente la información obtenida fue tratada en términos de matriz y sometida al análisis con PAUP 4.0b.10 (12).

\section{RESULTADOS}

La amplificación mediante PCR de los elementos Alu: STK1, HBGF y VP permitió obtener productos ortólogos para cada especie con variación de relativamente pocos pares de bases dentro de cada una (Figura 2 y Tabla 1).

Figura 2. Amplificación del marcador Alu HBGF para Saimiri sciureus, Lagothrix lagotricha $y$ Alouatta palliata

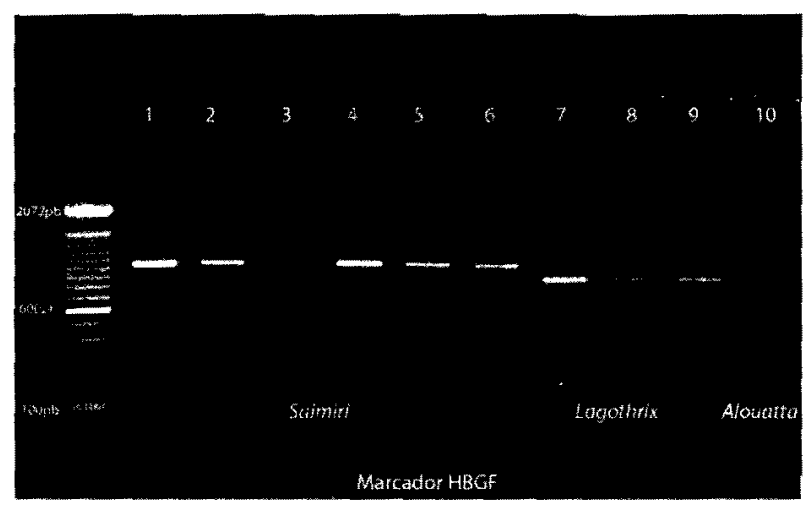

Los productos de amplificación mediante PCR para el marcador HBGF oscillan entre 1073, 1080 y $1093 \mathrm{pb}$ para Saimiri. En Lagothrix se amplificó un producto de $948 \mathrm{pb}$, mientras que para Alouatta se obtuvo un producto de $968 \mathrm{pb}$
Con esta información se procedió a realizar el análisis filogenético mediante Neighborjoining. El árbol obtenido (Figura 3) permitió dilucidar relaciones de parentezco entre las especies analizadas.

\section{DISCUSIóN}

El hecho de haber amplificado mediante PCR tres tipos de elementos Alu en el genoma de las especies de platirrinos analizadas en este trabajo respalda fuertemente la monofilia propuesta para el infraorden $(5,6,7,8$, 9).

Por otra parte la presencia de productos de amplificación de diferentes dimensiones para cada especie estudiada sugiere que las transposiciones derivadas de este tipo de elementos Alu han tenido lugar durante la evolución de los monos del Nuevo Mundo.

Las relaciones inferidas mediante el análisis de Neighbor-joining evidencian por $\mathbf{u}$ na parte, mayor cercanía entre Cebus y Saimi$r i$, sosteniendo el clado Cebus - Saimiri propuesto por evidencias citogenéticas (13) y moleculares $(6,7,8,14)$ y por otra entre Lagothrix, Ateles y Alouatta respaldando el posicionamiento de estos tres géneros en la familia Atelidae.

Considerando que los monos del Nuevo Mundo podrían con seguridad ser los protagonistas de un importante evento de radiación que

Tabla 1. Productos de amplificación mediante PCR para los elementos Alu STK1, HBGF y VP en varias especies de platirrinos ecuatorianos

\begin{tabular}{|l|l|l|l|}
\hline Especie & Elemento Alu STK1 & Elemento Alu HBGF & Elemento Alu VP \\
\hline Cebus albifrons & $1660-1686 \mathrm{pb}$ & $1040-1052 \mathrm{pb}$ & $870-880 \mathrm{pb}$ \\
\hline Saimiri sciureus & $1514-1577-1595 \mathrm{pb}$ & $1073-1080-1093 \mathrm{pb}$ & $818-858-880 \mathrm{pb}$ \\
\hline Ateles belzebuth & $1215 \mathrm{pb}$ & $877 \mathrm{pb}$ & $890 \mathrm{pb}$ \\
\hline Ateles fusciceps & $1200 \mathrm{pb}$ & $866 \mathrm{pb}$ & $890 \mathrm{pb}$ \\
\hline Lagotrhrix lagotricha & $1159-1200 \mathrm{pb}$ & $948 \mathrm{pb}$ & $800-807 \mathrm{pb}$ \\
\hline Alouatta palliata & $1277 \mathrm{pb}$ & $968 \mathrm{pb}$ & $882 \mathrm{pb}$ \\
\hline
\end{tabular}


Figura 3. Arbol de Neigbor-Joining para los elementos Alu: HBGF, VP y STK1 analizados en las especies: Cebus albifrons, Saimiri sciureus, Ateles belzebuth, Ateles fusciceps, Alouatta palliata y Lagothrix lagotricha.

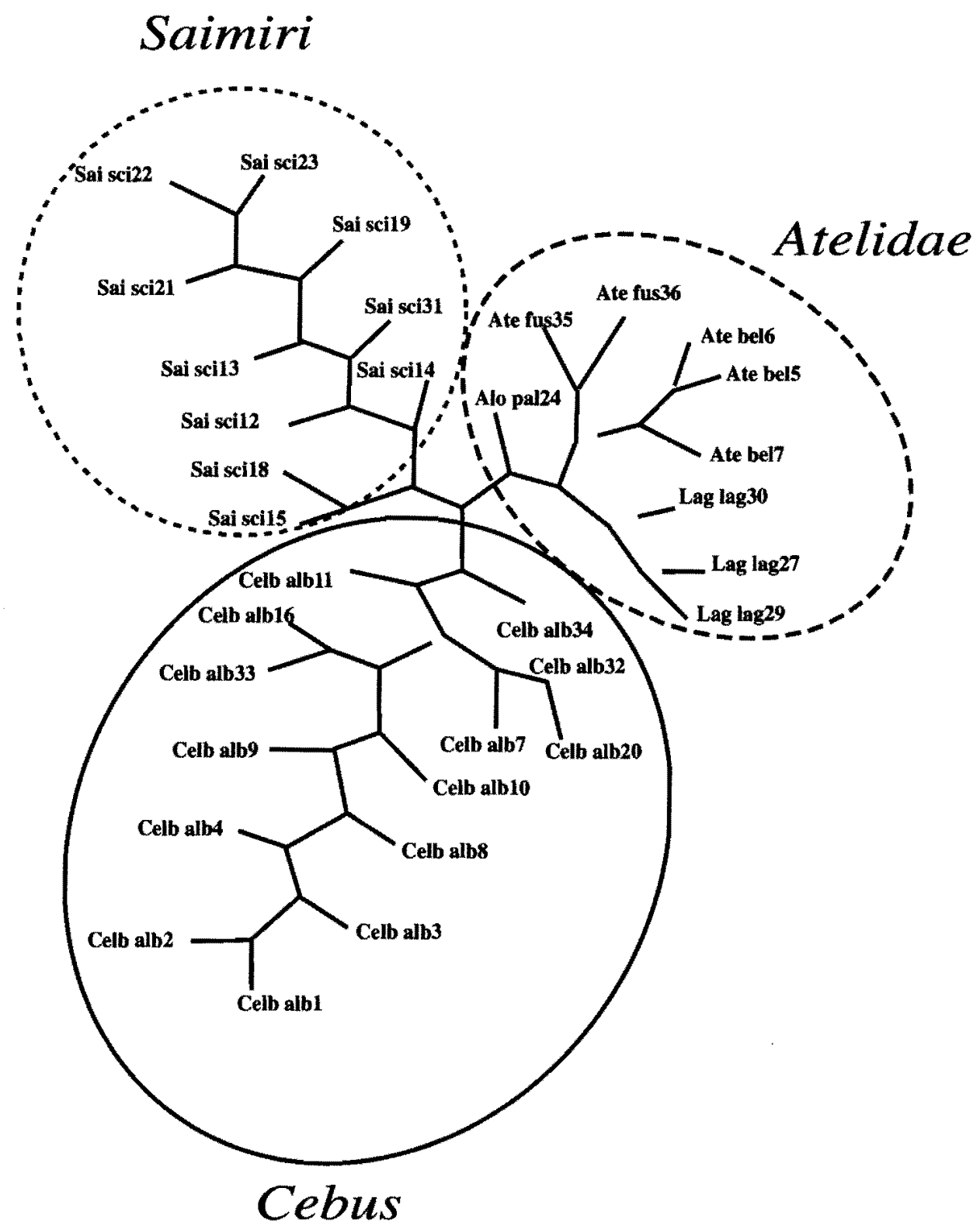

les permitió ocupar nichos ecológicos muy variados y divergir dramáticamente desde hace aproximadamente 40 millones de años, (11) es necesario abordar el análisis de su filogenia a la luz de varias fuentes de información genómica, así como de otros parámetros biológicos.

La información obtenida en el presente trabajo ha sido sin duda de interés para verificar la presencia de una dinámica transposicional con valor filogenético en el genoma de primates y para entender mejor las relaciones entre especies. No obstante esta información será ampliada a un mayor número de especies y será integrada a aquella proveniente de otros marcadores genómicos, que están siendo utilizados ya al momento, con el fin de aclarar la intrincada filogenia de los platirrrinos.

\section{Agradecimientos}

Se agradece al Dr. Andrés Ortega de la Fundación Zoológica de Guayllabamba por su colaboración en la obtención del material biológico utilizado en esta investigación. 


\section{REFERENCIAS}

1.- TRTKOVA, K.; MAYER, W.; O'HUIGIN, C. \& JAN KLEIN. Mhc - DRB genes and the origin of New World Monkeys. Molecular Phylogenetics and Evolution, 1995; 64: $408-419$.

2.- HOULE, A. The origin of Platyrrhines: an evaluation of the Antartic scenario and the floating island model. American Journal of Physical Antropology, 1999; 109:541-559.

3.- SCHRAGO, C. \& RUSSO, C. Timing the origin of New World Monkeys. Molecular Biology and Evolution, $2003 ; 20$ (10): 1620-1625.

4.- GOODMAN, M; PORTER,C; CZELUSNIAK, J.; PAGE, S.; SCHNEIDER, H.;SHOSHANI, J.; GUNNELL, G. \& GROVES, C. Towards a phylogenetic classification of primates based on DNA evidence complemented by fossil evidence. Molecular Phylogenetics Evolution, 1998; 9.585-598.

5.- HOROVITZ, I. \& MEYER, A. Sistematics of New World Monkeys (Platyrrhini, Primates) based on $16 \mathrm{~S}$ mitochondrial DNA sequences: a comparative analysis of different weighting methods in cladistic analysis. Molecular Phylogenetics Evolution, 1995; 4: 448-456.

6,- HOROVITZ, I.; ZARDOYA, R. \& MEYER, A. Platyrrhine systematics: a simultaneous analysis of molecular and morphological data. American Journal of Physical Antropology, 1998; 106: 261-268.

7.- PORTER, C.; SAMPAIO, I.; SCHNEIDER, H.; SCHNEIDER, M.; CZELUSNIAK,J. \& GOODMAN, M. Evidence on primate phylogeny from epsilon-globin gene sequences and flanking regions. Journal of Molecular Evolution, 1995; 40:30-55.
8. PORTER, C.; CZRLUSNIAK, J.; SCHNEIDER, H.; SCHNEIDER, M.; SAMPAIO, L. \& GOODMAN, M. Sequences of epsilon globin gene : implication for systematics of the marmosets and other New World primates.Gene, 1997; 205:59-71..

9.- SHCHNEIDER, H.; SHCNEIDER, M. P. C.; SAMPAIO, I.; HARADA., M. L.; STANHOPE, M.; CZELUSNIAK, J. \& GOODMAN, M. Molecular phylogeny of the New World Monkeys (Platyrrhini, Primates). Molecular Phylogenetics and Evolution, 1993; 2: 225 .

10.- TIRIRA, D. (1999) Mamíferos del Ecuador. Publicación especial $\mathrm{N}^{\circ} 2$. Museo de Zoología de la Pontificia Universidad Católica del Ecuador. Quito. pp. 67-72

11.- SINGER, S. S.; SCHMITZ, J.; SCHWIEGK, C. \& ZISCHLER, H. Molecular cladistic markers in New World monkeys phylogeny (Platyrrhini, Primates). Molecular Phylogenetics and Evolution, 2002; 26: 490-501

12.- SWOFFORD D., PAUP 4.0.b.10. Phylogenetic Analysis using Parsimony and other methods. Computer Program distributed by Sinauer Associates. Sunderland, Massachusetts. 2001.

13.- CHIARELLI, A. B., The karyology of South American Primates and their relationship to African and Asian species. In Ciochon, R.L., Chiarelli, A.B. (Eds.), Evolutionary Biology of the New World Monkeys and Continental Drift. Plenum Press. New York, 1980; pp 387-398.

14. HARADA, M.; SCHNEIDER. H.; SCHNEIDER, M.; SAMPAIO, I.; CZELUSNIAK \& J.; GOODMAN, M. DNA evidence on the phylogenetic systematics of New World Monkeys :support for the sister-grouping of Cebus and Saimiri from two unlinked nuclear genes. Molecular Phylogenetics Evolution, 1995; 4: 331-349. 